\title{
Comparison of Forward Chaining and Hill Climbing Methods in Blood Disease Diagnosis Expert Systems
}

\author{
Lydia Natalia Kristiani ${ }^{1}$, Erdhi Widyarto Nugroho', \\ Albertus Dwiyoga Widiantoro ${ }^{3}$ \\ ${ }^{1,2,3}$ Departmen of Information System, Soegijapranata Catholic University \\ 1,2,3J1. Pawiyatan Luhur Sel. IV No.1, Bendan Duwur, Kota Semarang, Jawa Tengah 50234 \\ ${ }^{1}$ Inataliakristiani@gmail.com \\ ²erdhi@unika.ac.id \\ ${ }^{3}$ yoga@unika.ac.id
}

\begin{abstract}
Blood disease is a condition in which one or several parts of the blood can't function normally. Blood disease itself is classified as quite mild but also some are classified as serious diseases and are usually genetic. Sometimes people underestimate the symptoms of mild illnes and lazy to see a doctor or laboratory because they think it troublesome and need to spend money. Therefore an early diagnosis of symptoms that may be related to blood disease is needed, so people can be alert and also prevent severe blodd disease. That's why we need an expert system application that can help people diagnose and be aware of diseases that related to blood.
\end{abstract}

Keywords - Blood, blood disease, expert systems.

\section{INTRODUCTION}

Blood disorder or in the medical world commonly known as hematological disorders are a condition in which one or several parts of the blood can't function normally. This can lead to acute or even chronic abnormalities. According to the ICD (International Classification of Disease) blood disorders enter the D50-D89 block about blood diseases, blood-forming organs, and certain abnormalities involving the immune system[1]. Lack of public understanding and awareness of blood disorders and their symptomps cause people's awareness of this disease to be lacking. Not only that, sometimes people are also lazy to check themselves into hospitals or laboratories because they have to wait in line and spend money. To prevent blood disorders from getting worse, people must know the cause, symptoms, and treatment. One of the things that can be done to help diagnose and understand blood disease is to build an expert system to diagnose blood diseases.

An expert system is a system designed to be able to adopt human knowledge into a computer so that it can mimic or match the abilities of an expert[2]. There are various methods used for expert systems, namely AHP (Analytical Hierarchy Process), BFS (Breadth First Search), DFS (Depth First Search), Backward Chaining, and Forward chaining methods[3].

Because of that, the writer get the idea to make an expert system to diagnose the blood disease with two methods, forward chaining and hill climbing while comparing the two methods.

\section{LITERATUR REVIEW \\ A. Expert System}

Expert system is one of the fields of articial intelligence (AI). This system focuses on the development and implementation of computer programs that can mimic or produce human activities that require thinking, some skills and experiences collected. Usually expert systems are used to diagnose, help decision making, interpretation and analysis[4]. Expert systems are interactive decision tools that use facts and heuristics to solve difficult decision problems that are obtained from an expert[5]. 


\section{B. Forward Chaining}

Forward chaining is one of expert systems method that search or find solution through problems. In other words, this method processes the consideration of the facts and then leads to a final conclusion based on the fact[6].

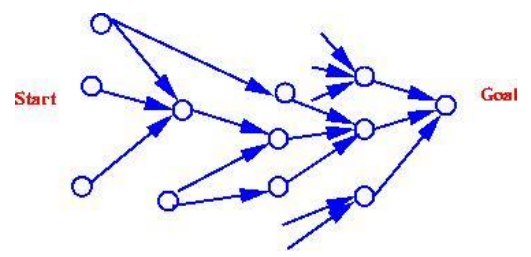

Figure 2.1 Forward chaining scheme

Forward chaining is usually reffered to as bottom-up reasoning, because this method considers from the facts or evidence at the lower level, then leads to conclusions at the top level based on these facts. Forward chaining is useful to apply if there are unlimited potential solutions such as configuration and planning issues[7]. In the health sector, forward chaining method itself has been widely used in making expert systems, such as: expert systems for diagnosis kidney disease, expert systems for pediatric disease, and expert systems for diagnosing diseases caused by mosquitoes.

\section{Hill Climbing}

Hill climbing is a heuristic search used for mathematical optimization problems in the field of artificial intelligence[8]. The hill climbing method itself is a variation of the DFS method.

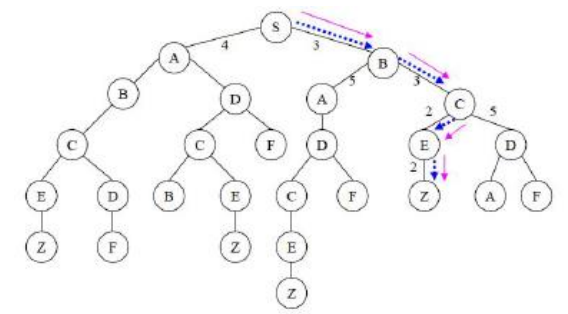

Figure 2.2 Hill climbing scheme

Exploration of decisions is done by looking for paths that reduce costs to lead to final conclusion. In other words, this method minimizes the number of conditions it occupies without having to see the node afterwards[9]. Although more advanced algorithms can provide better results, in some situations hill climbing can function well[10]. In the health sector, hill climbing method itself has been used in making expert systems for diagnosing kidney disease and diagnosing peripheral neuropathy.

\section{Blood}

Blood is a fluid that moves through the vessels of the circulatory system. Blood consists of plasma in which the following highly-specialized cells are suspended: red blood cells (erythrocytes), white blood cells (leucocytes), and platelets[11]. Cells and platelets make up about $45 \%$ of human blood, while plasma forms $55 \%$. Blood has many different functions, including transporting oxygen and nutrients to the lungs and tissue, excessive blood loss, carrying cells and antibodies that fight infection, carrying waste products to the kidneys and liver that filter and cleanse blood, and regulate body temperature[12].

\section{E. Blood Disorders (Hematology)}

Disorders that affect blood are called blood disorders or hematological disorders. There are many types of blood disorders and can affect the quantity and function of cells in the blood or proteins in the blood clotting system or the immune system. Blood abnormalities that infect those who have asymptomatic causing no significant decrease[13].

\section{F. Intelligent System}

Intelligent system are fairly common systems and identify a broad class of intelligence and miniature devices that are usually automatic and make it easy for users to do something[14]. Definitions for intelligent systems that are commonly used emphasize the externally visible functionality and heterogeneous components needed to implement intelligent systems, specifically direct and indirect sensing and their respective drive and interface functions[15].

\section{RESEARCH METHODOLOGY}

Research done by first observing the methods that used in making expert systems 
in the health sector, after that collect data and information from literature review and interview with experts named dr. Maya Yanuarty and dr. Ria Lupitasari from faculty of medicines Soegijapranata catholic university about diseases that related to blood for decide the design of the application. After the data collected is completed, next is making the database to store all the information obtained about blood disease and start to design the application. After the design was reviewed and accepted, next step is making the prototype application with PHP and HTML programming language. After that the application is reviewed and tested for get rid of the bug. The last after the prototype application is completed it's ready to be use.

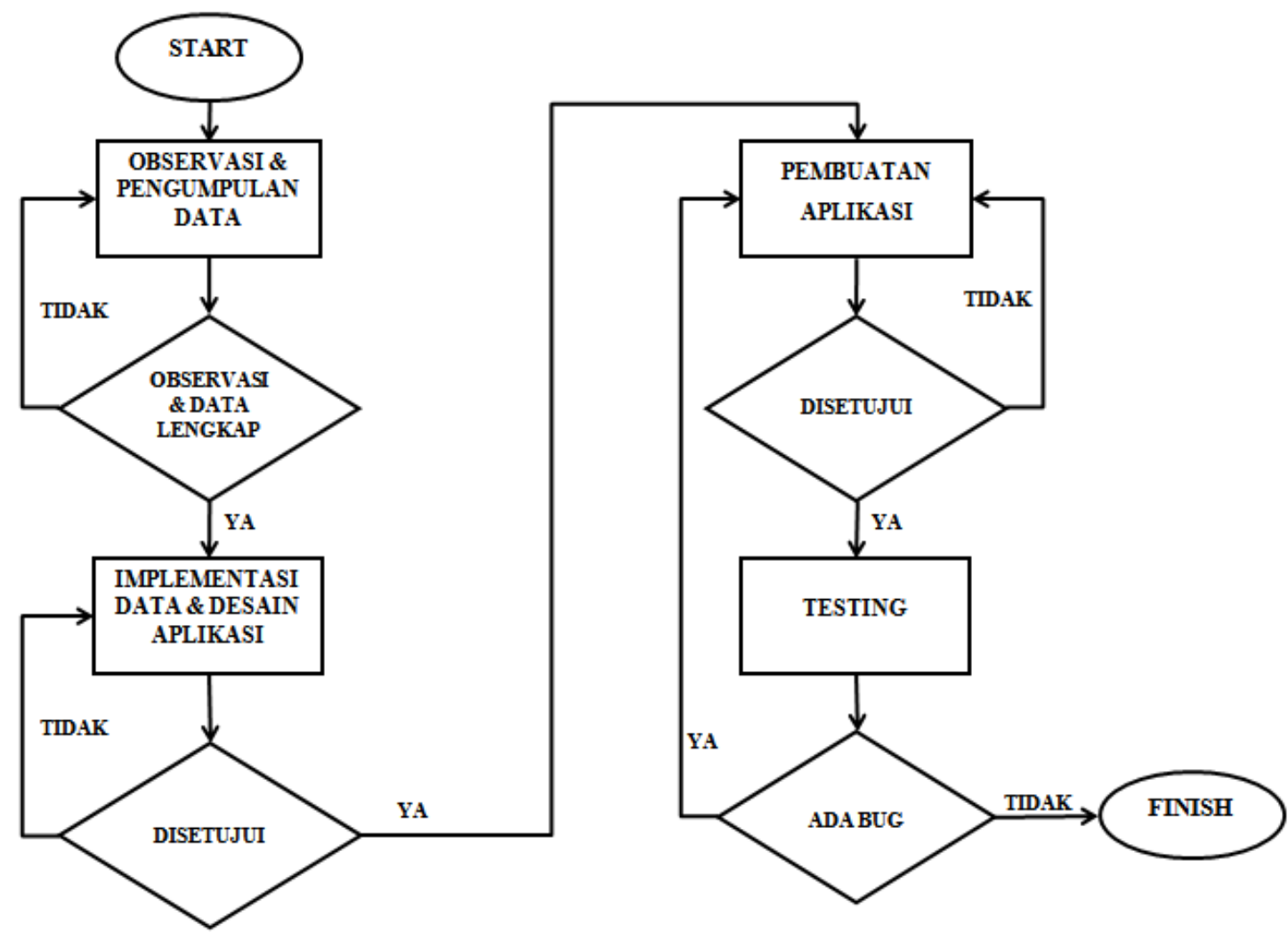

Figure 3.1 Flow of making the application

Next the prototype application tested to people to see the result of the application. The object of this research is people with an age limit of 21-50 years, number of the audience is 32. The method of this research is using questionnaire, literature review and observation. Primary data is collected from questionnare and interview with doctors, and secondary data collected from literature review.
IV. RESULTS AND DISCUSSION

\section{A. Profile of Respondent}

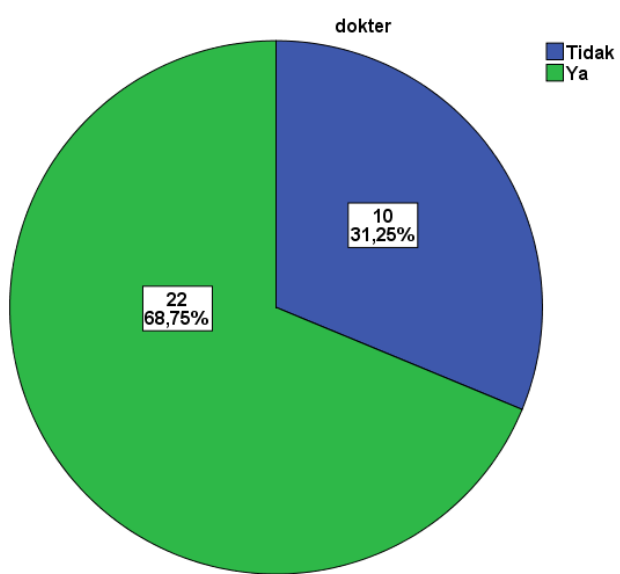

Figure 4.1Experience of check-up with doctor 
Many respondents have experience conducting medical examinations with doctors. This is indicated by the number of respondents who had a health check with doctor was 22 of 32 people.

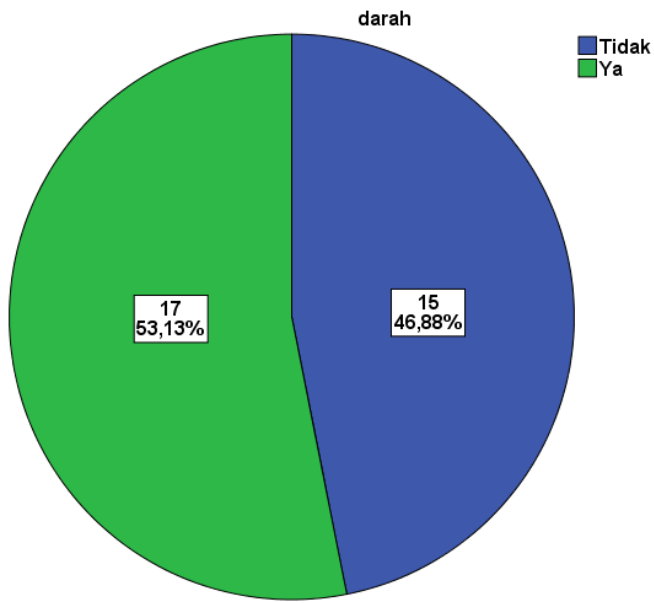

Figure 4.2 Experience of blood check at laboratory

The data above shows that the number of people who have done blood checks is 17 people, which is almost equal to those who have never, that is 15 people. The meaning of done a blood checking here is different with checking blood type, what is meant is done blood checking to find out the history of the disease.

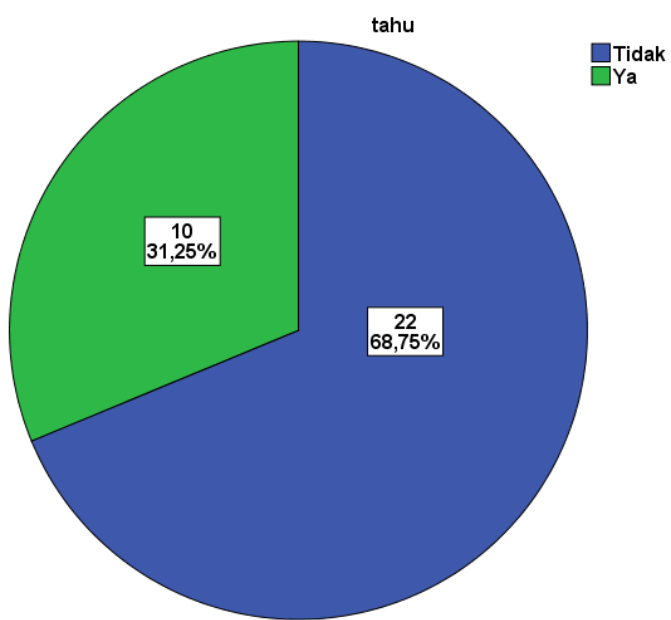

Figure 4.3 Knowing there is an expert system that can be used to diagnose disease

The data obtained shows that the number of people who dont know about the existence of an expert system for diagnosis, the number is greater with a total of 22 people compared to the number of people who already know with a total of 10 people. Knowing in this question is mean for people who already know about an expert system that can be used to diagnose disease even though they have never see or use it directly.

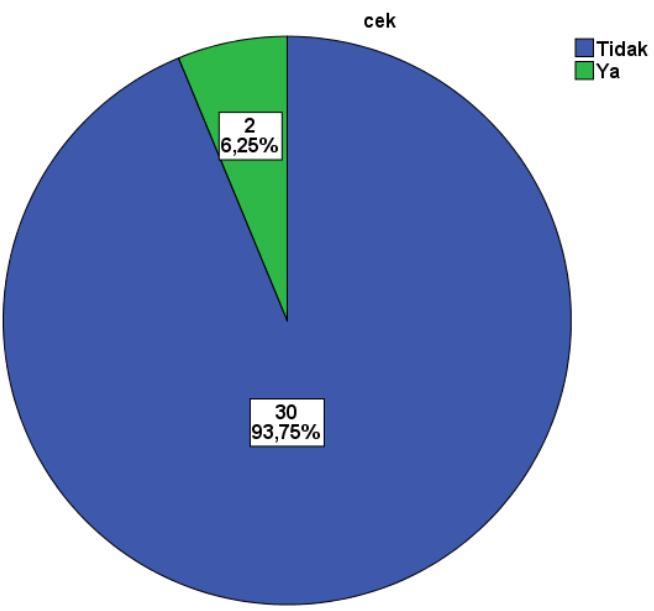

Figure 4.6 Experience of checking health with expert system

The data above shows that the majority of respondents with total 30 people have never done a health check using an expert system. While those who have done halth check with an expert system are only 2 people.

\section{B. Application}

Result of the prototype application is an experts system for diagnosing blood disease. In this application user can make diagnoses with two different methods, forward chaining and hill climbing and also can see information about blood diseases and herbs.

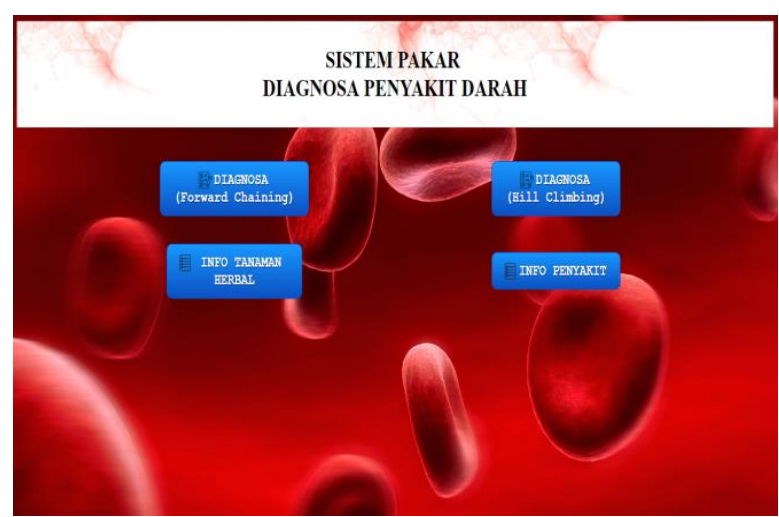

Figure 4.7 experts system for diagnosing blood disease

On the diagnosis menu with the forward chaining method, user will be given instruction for use, before starting the diagnosis. After that user will make a diagnosis by selecting the perceived 
symptoms based on the categories that have been made.

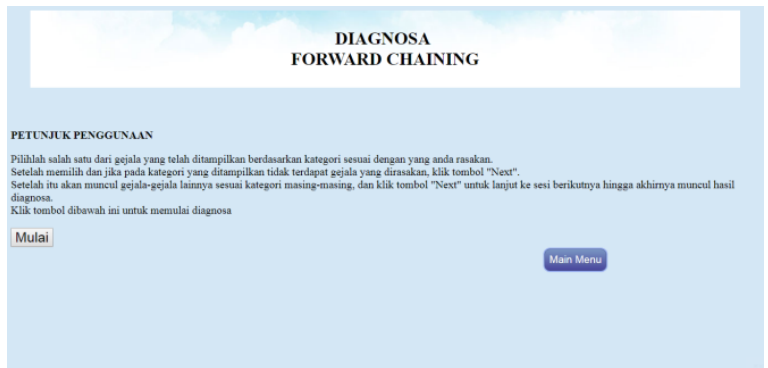

Figure 4.9 forward chaining diagnostic page 1

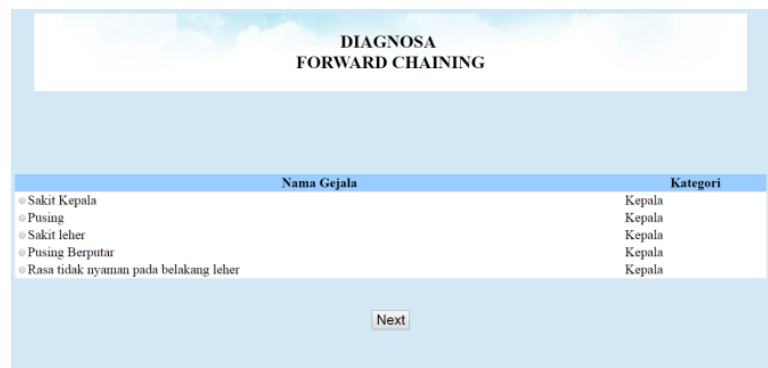

Figure 4.10 forward chaining diagnostic page 2

After user has finished the diagnostic process using the forward chaining method, the result page will appear. On this page user can see the symptoms that have been previously chosen, the possibility of the disease suffered along with the details and percentages.

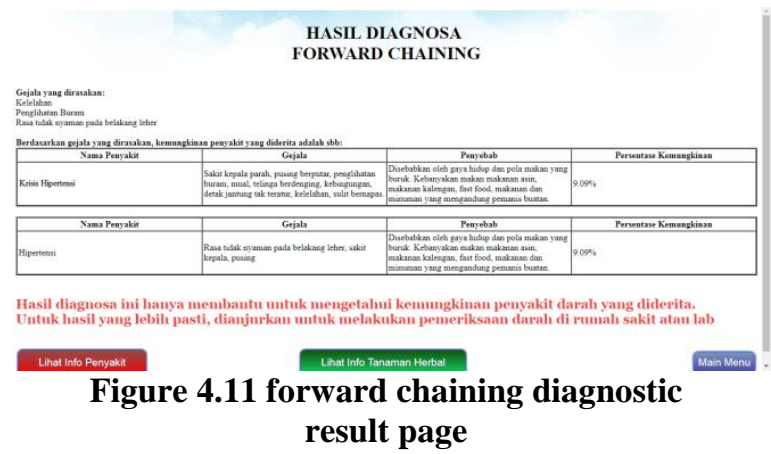

On the diagnosis menu with the hill climbing method, user will be presented with all the symptoms and must choose one of the most dominant symptoms to make a diagnosis.

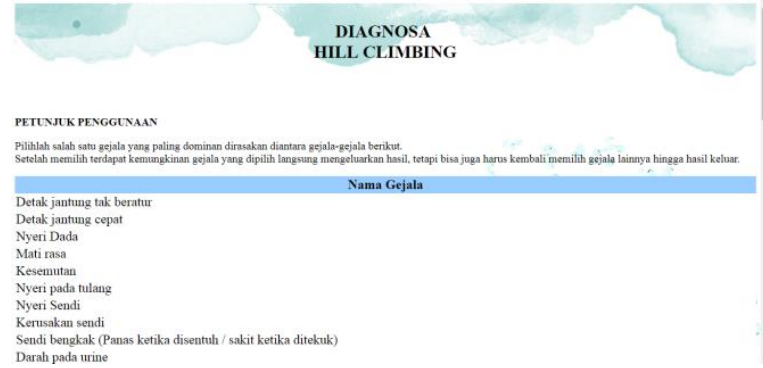

Figure 4.12 hill climbing diagnostic page

If the chosen symptoms are the initial and final nodes the results of diagnosis will immediately come out, however, if the chosen symptoms are not the end node, user must choose the next symptom until the final diagnosis result appears.

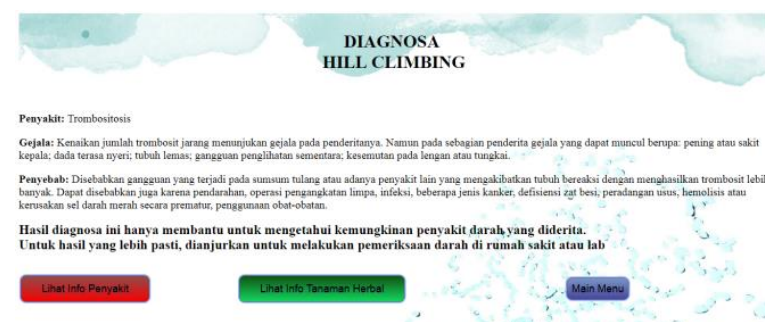

Figure 4.13 hill climbing diagnostic result page

On the information menu about blood diseases and herbs, user can see various blood diseases and herbal plants along with the detailed information.

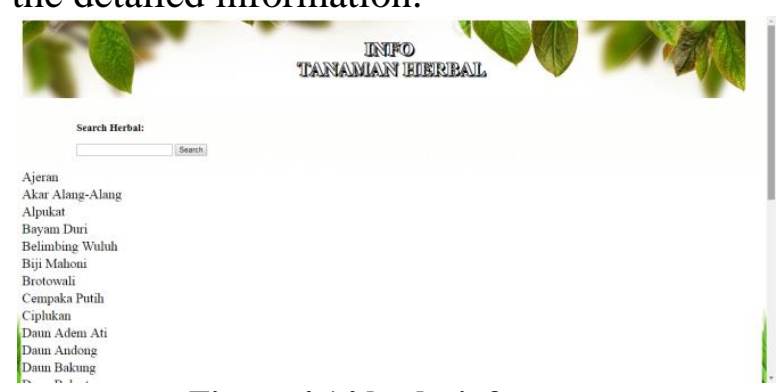

Figure 4.14 herbs info page

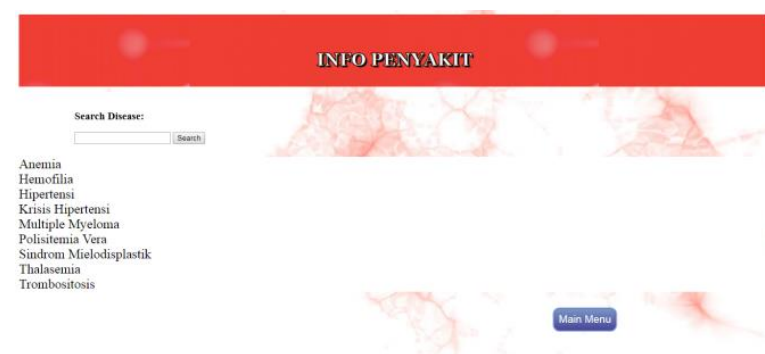

Figure 4.15 diseases info page 
On the info menu about herbal plants, the detailed information is complemented with Figure of the plants.

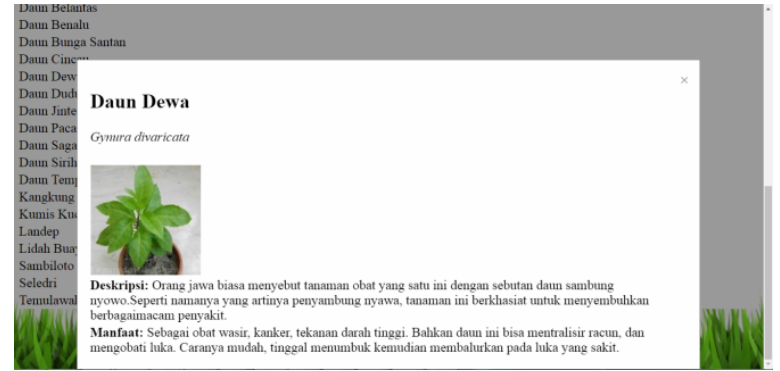

Figure 4.15 diseases info page

\section{Review of the application}

\begin{tabular}{|c|c|c|c|c|c|c|}
\hline & Melihat & Interest & Memudahkan & Understanding & Usability & Usefulness \\
\hline Average & 4.09 & 4.22 & 4.09 & 3.75 & 4.06 & 4.16 \\
\hline
\end{tabular}

Table 4.1 Review of the expert system for diagnosing blood disease

Above is a the review from the 32 respondents with an age limit of 21-50 years. Scale used is 1 to 5 . From data its show that expert system application for diagnosing blood disease get enough positve review.

\section{Comparison of forward chaining method and hill climbing method}

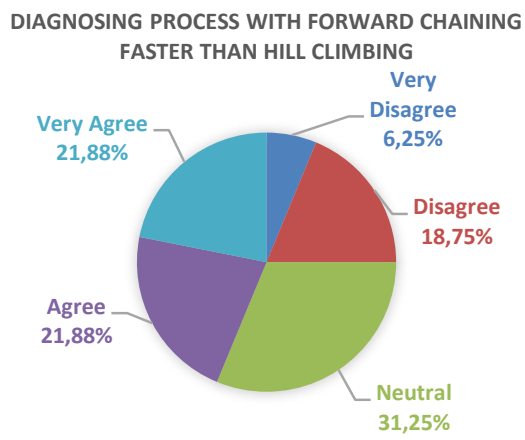

Figure 4.16 comparison of diagnosis speed

Above is the opinion of users who have tried the forward chaining and hill climbing methods in the expert system application of diseases, $21.88 \%$ of respondents felt the diagnosis process with forward chaining method was very faster than hill climbing method. Then $21.88 \%$ chose to agree that the diagnosis process with forward chaining method faster than hill climbing method. Then as many as $31.25 \%$ of respondents chose to answer neutral. Respondent who didnt agree that the diagnosis process with the forward chaining method faster than hill climbing method is $18.75 \%$, and those who feel that the diagnosis process with hill climbing method is faster than forward chaining method is $6.25 \%$. Based on these results, it can be concluded that the majority of respondents feel the diagnosis process with the forward chaining method is faster.

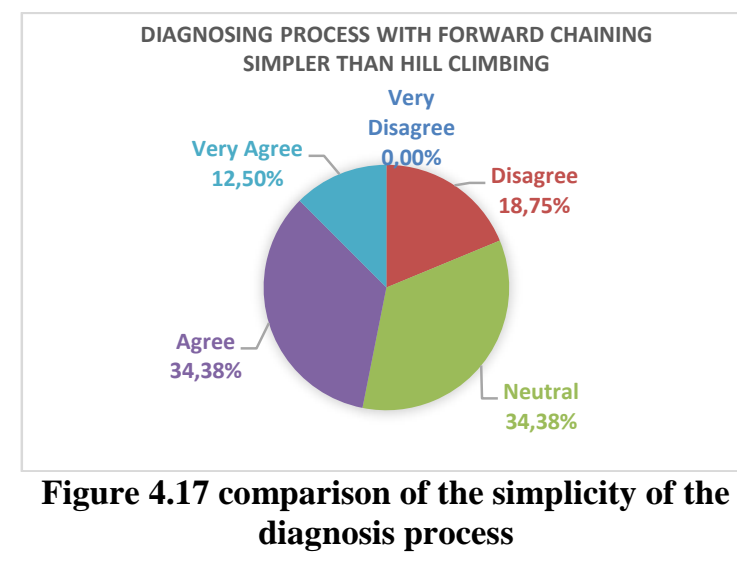

Based on the simplicity in the process of diagnosis with the forward chaining and hill climbing methods in the application of expert system for diagnosing blood disease, a total of $12.5 \%$ of respondents very agreed that the diagnosis process with forward chaining method was simpler than hill climbing method. Then as many as $34.38 \%$ of respondents felt agree. Respondents who chose neutral is $34.38 \%$. And as much as $18.75 \%$ disagree that the forward chaining method is simpler than hill climbing method, because according to them the diagnosis process with hill climbing method is simpler. From these results it can be concluded that the majority of respondents feel the 
diagnosis process with forward chaining method is simpler.

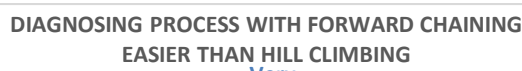

Figure 4.18 comparison of the ease of use

Based on the ease of use with the forward chaining and hill climbing methods on the application of expert system for diagnosing blood disease, $15.63 \%$ of respondents very agreed that the use of the diagnostic process with the forward chaining method is easier than hill climbing method. Then $40.63 \%$ of respondents felt agreed. As many as $28.13 \%$ choose neutral. However, there are $12.5 \%$ of respondents who disagree and $3.13 \%$ of respondents very disagree that the forward chaining method is easier than hill climbing method. From these results it can be concluded that the process of using the forward chaining method on expert system application to diagnose blood disease is easier.

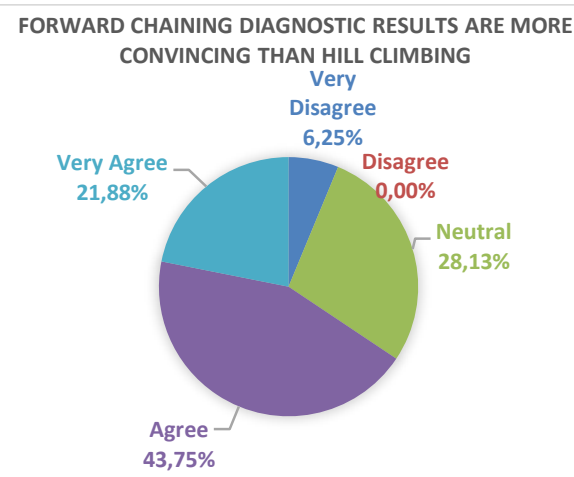

Figure 4.19 comparison of the results

Based on the final results of the diagnosis process, a total of $21.88 \%$ of respondents very agreed if the results of the diagnosis with forward chaining method were more convincing than the results of the diagnosis with hill climbing method. Then $43.75 \%$ chose to agree, and $28.13 \%$ chose neutral. But there were $6.25 \%$ of respondents who felt very disagree that the final results of the diagnosis with forward chaining method were more convincing than hill climbing method. From these results it can be concluded that the final results of the diagnosis with forward chaining method, the results are more convincing because the user can choose what symptoms they felt based on the existing categories and after that user can find out the percentage of possible illnesses.

\section{CONCLUSIONS}

The application of expert system for diagnosing blood disease can facilitate in diagnosing the possibility of the disease suffered, and this application is very useful because it is not only to diagnose the possibility of the disease suffered but also provide useful data and information along with the datails that can be used for knowledge. After trying to diagnose with 2 method, users thinks the process of diagnosing blood diseases with forward chaining method is felt to be faster and simpler. It is easier for the user because the user is given a choice of symptoms based on the category, so user not confused to choose the symptoms that they feel. The final results of the diagnosis with the forward chaining method are more convincing because the systematic diagnosis process, where the user can choose the symptoms that are felt based on the existing categories, then the percentage of the probability of the disease based on the chosen symptoms.

\section{REFERENCES}

[1] World Health Organization, International Statistical Classification of Diseases and Related Health Problems. 10th Revision, vol. 41. 1992.

[2] M. Akram, I. A. Rahman, and I. Memon, "A Review on Expert System and its Applications in Civil Engineering," Int. J. Civ. Eng. Buit Environ., vol. 1, no. 1, 2014. 
[3] A. Al-ajlan, "The Comparison between Forward and Backward Chaining," Int. J. Mach. Learn. Comput., vol. 5, no. 2, 2015.

[4] Z. Alma and L. N. Gumilyov, "The Methodology of Expert Systems," IJCSNS Int. J. Comput. Sci. Netw. Secur., vol. 14, no. 2, pp. 62-66, 2014.

[5] S. Gupta and R. Singhal, "Fundamentals and Characteristics of an Expert System," Int. J. Recent Innov. Trends Comput. Commun., vol. 1, no. 3, pp. 110-113, 2013.

[6] G. Abram, F. Suwarso, G. S. Budhi, and L. P. Dewi, "Sistem Pakar untuk Penyakit Anak Menggunakan Metode Forward Chaining."

[7] B. Haval and S. Mzori, "Forward and Backward Chaining Techniques of Reasoning in Rule-Based Systems," Eastern Mediterranean University, 2015.

[8] U. Rawat, "Introduction to Hill Climbing | Artificial Intelligence." [Online].

Available: https://www.geeksforgeeks.org/introd uction-hill-climbing-artificialintelligence/amp/.

[9] D. D. W. Pakpahan, "Sistem Pakar Mendiagnosa Penyakit Neuropati Perifer Menggunakan Metode Hill Climbing Pada Rumah Sakit Sari Mutiara," pp. 202-206, 2011.

[10] H. Climbing, "Local Search Algorithms \& Optimization Problems."

[11] World Health Organization, "Obstetrics," Clin. Use Blood Med. Obstet. Paediatr. Surg. Anaesth. Trauma Burn., pp. 209-227, 2002.

[12] A. S. of Hematology, "Blood Basics." [Online]. Available: http://www.hematology.org/Patients/B asics/.

[13] M. G. H. David J. Kuter, MD, DPhil, Professor of Medicine, Harvard Medical School; Chief of Hematology, "Overview of Blood Disorders." [Online]. Available: https://www.merckmanuals.com/home /blood-disorders/symptoms-anddiagnosis-of-blooddisorders/overview-of-blooddisorders.

[14] A. Sassone, M. Grosso, M. Poncino, and E. Macii, "Smart Systems Integration and Simulation," pp. 5-22, 2016.

[15] C. Lanting and A. Lionetto, "Smart Systems and Cyber Physical Systems paradigms in an IoT and Industrie/y4.0 context," Proc. 2nd Int. Electron. Conf. Sensors Appl., p. S5002, 2015. 